Research Article

\title{
The complete mitochondrial genome sequence of the black-capped capuchin (Cebus apella)
}

\author{
Xiao-xin Bi, Ling Huang, Mei-dong Jing, Li Zhang, Pei-yong Feng and Ai-yun Wang \\ College of Life Sciences, Ludong University, Yantai, Shandong, P.R. China
}

\begin{abstract}
The phylogenetic relationships of primates have been extensively investigated, but key issues remain unresolved. Complete mitochondrial genome (mitogenome) data have many advantages in phylogenetic analyses, but such data are available for only 46 primate species. In this work, we determined the complete mitogenome sequence of the black-capped capuchin (Cebus apella). The genome was 16,538 bp in size and consisted of 13 protein-coding genes, 22 tRNAs, two rRNAs and a control region. The genome organization, nucleotide composition and codon usage did not differ significantly from those of other primates. The control region contained several distinct repeat motifs, including a putative termination-associated sequence (TAS) and several conserved sequence blocks (CSB-F, E, D, C, B and 1). Among the protein-coding genes, the COII gene had lower nonsynonymous and synonymous substitutions rates while the ATP8 and ND4 genes had higher rates. A phylogenetic analysis using Maximum likelihood and Bayesian methods and the complete mitogenome data for platyrrhine species confirmed the basal position of the Callicebinae and the sister relationship between Atelinae and Cebidae, as well as the sister relationship between Aotinae (Aotus) and Cebinae (Cebus/Saimiri) in Cebidae. These conclusions agreed with the most recent molecular phylogenetic investigations on primates. This work provides a framework for the use of complete mitogenome information in phylogenetic analyses of the Platyrrhini and primates in general.
\end{abstract}

Key words: Cebus apella, control region, mitochondrial genome, phylogenomics.

Received: September 10, 2011; Accepted: March 1, 2012.

\section{Introduction}

The phylogenetic analysis of primates has attracted much attention because of the potential for defining and understanding the processes that mold, shape and transform the human genome. Primate taxonomy based on morphological, adaptive, bio-geographical, reproductive and behavioral traits, with inferences from the fossil record (Goodman et al., 1998; Groves, 2001; Wilson and Reeder, 2005), is complex. Molecular genetic data have been used to infer many relationships among primate taxa (Hayasaka et al., 1988; Schneider et al., 1993; Moreira, 2002; Opazo et al., 2006; Hodgson et al., 2009; Wildman et al., 2009; Perelman et al., 2011). The phylogenetic relationships of Neotropical primates (Platyrrhini) in the suborder Haplorrhini are not as well understood as those of their closest relatives, the Old World monkeys and apes (Catarrhini) (Stewart and Disotell, 1998; Raaum et al., 2005). The monophyly of three major lineages (Atelidae, Cebidae and Pitheciidae) within the platyrrhines has been confirmed, but the relationships among these three groups have been difficult to resolve (Horovitz et al., 1998; Steiper and

Send correspondence to Ling Huang. College of Life Sciences, Ludong University, 186\#, Hongqi Central Road, Yantai 264025 Shandong, P.R. China. E-mail: Huangl@Idu.edu.cn.
Ruvolo, 2003; Ray et al., 2005; Opazo et al., 2006; Schrago, 2007). The most recent studies support a basal division of the Pitheciidae and a sister relationship between Atelidae and Cebidae (Hodgson et al., 2009; Perelman et al., 2011). The relationships among different genera in the Atelidae and Pitheciidae are well-established (Opazo et al., 2006; Wildman et al., 2009; Perelman et al., 2011) whereas the results for the Cebidae are more controversial, and various possible relationships among the Aotinae, Callitrichinae and Cebinae have been inferred (Kay, 1990; Schneider et al., 1993; Moreira, 2002; Opazo et al., 2006; Hodgson et al., 2009; Wildman et al., 2009; Perelman et al., 2011). The most recent studies suggest a sister relationship between the Aotinae and Callitrichinae and a sister relationship between Aotinae/Callitrichinae and Cebinae (Cebus/Saimiri) (Hodgson et al., 2009; Perelman et al., 2011). The taxonomy of the genus Cebus is controversial, with different opinions on the classification of species within this group (Mittermeier and Coimbra-Filho, 1981; Groves, 2001; Silva Júnior, 2002); the phylogenetic relationships among species also remain unresolved, despite molecular and cytogenetic studies of this issue (Moreira, 2002; Amaral et al., 2008; Garcia-Cruz et al., 2011; Nieves et al., 2011; Perelman et al., 2011). 
In molecular systematics, the topology structures of the phylogenetic trees vary with the molecular markers used and the number of taxa involved. A comparison of related data from different taxa can be helpful in clarifying controversial topologies. In recent years, the mitochondrial genome (mitogenome) has been widely used in phylogenetic studies because of its matrilineal inheritance, lack of extensive recombination and accelerated nucleotide substitution rates (Ingman et al., 2000; Zhang et al., 2008). A complete mitogenome contains more information on the evolutionary history of a species than individual genes, and the use of this genome in phylogenetic analyses reduces stochastic errors and minimizes the effect of homoplasy (Campbell and Lapointe, 2011). Mitogenomes can also be used as a source of molecular markers in conservation studies of endangered species (Krajewski et al., 2010; Meyer et al., 2011). To date, the complete mitogenomes of 46 primate species have been sequenced, including five platyrrhine species (Aotus lemurinus, Ateles belzebuth, Callicebus donacophilus, Cebus albifrons and Saimiri sciureus) (Arnason et al., 2000; Hodgson et al., 2009).

Cebus apella (Linnaeus, 1758), the tufted or blackcapped capuchin occurs only in South America (Colombia, Ecuador, Peru, Bolivia, Brazil, French Guiana, Suriname and Venezuela) (Fragaszy et al., 2004). C. apella is under severe pressure from hunting and habitat loss and fragmentation throughout its range, with a sharp decline in numbers in recent years; the species has been included in CITESAppendix II since the 1970s (Nijman et al., 2011).

Although several molecular phylogenetic and cytogenetic studies of $C$. apella have been reported (Moreira, 2002; Amaral et al., 2008; Wildman et al., 2009; Nieves et al., 2011; Perelman et al., 2011), the complete mitogenome sequence of this species has not yet been described. In this work, we determined the complete nucleotide sequence of the $C$. apella mitogenome and determined its genomic structure. We also compared the rates of nonsynonymous $(\mathrm{Kn})$ and synonymous $(\mathrm{Ks})$ substitutions in protein-coding genes (PCGs) with those of Homo sapiens and five other platyrrhine species. A phylogenomic tree that included six platyrrhine species confirmed the usefulness of complete mitogenome sequences for molecular phylogenetic investigations.

\section{Materials and Methods}

\section{Tissue samples and genomic DNA extraction}

Samples from one specimen of $C$. apella were collected from Kunming Zoo, Yunnan Province, China. The specimen was identified based on external characteristics, using the system of Groves (2001) and Nowak et al. (1999). Total genomic DNA was isolated from fresh muscle samples by using a Wizard Genomic DNA purification kit (Promega) according to the manufacturer's instructions.

\section{Mitochondrial DNA amplification by PCR}

The mitogenome was amplified by the polymerase chain reaction (PCR) technique. The entire mitogenome of C. apella was obtained by using 12 primer sets to amplify contiguous and overlapping segments (Table 1) (Sorenson et al., 1999; Ingman et al., 2000). All fragment sequences overlapped each other by at least $200 \mathrm{bp}$. PCR amplifications were done in a Mycycler Gradient thermocycler using a final volume of $50 \mu \mathrm{L}$ that contained 20-50 ng of genomic DNA $(0.5 \mu \mathrm{L}), 2.5 \mathrm{mM}$ of each dNTP $(4 \mu \mathrm{L}), 10 \mu \mathrm{M}$ of each primer $(1 \mu \mathrm{L}), 5 \mu \mathrm{L}$ of $10 \mathrm{x}$ buffer, $0.25 \mu \mathrm{L}$ of Taq polymerase $(5 \mathrm{U} / \mu \mathrm{L}$; Takara) and $38.3 \mu \mathrm{L}$ of sterile distilled water. The cycling parameters were: preliminary denaturation at $95{ }^{\circ} \mathrm{C}$ for $5 \mathrm{~min}$, followed by 35 cycles of denaturation at $95^{\circ} \mathrm{C}$ for $45 \mathrm{~s}$, annealing at $55^{\circ} \mathrm{C}$ for $45 \mathrm{~s}$, elongation at $72{ }^{\circ} \mathrm{C}$ for $2 \mathrm{~min}$, with a final elongation at $72{ }^{\circ} \mathrm{C}$ for $10 \mathrm{~min}$. The PCR products were electrophoresed on a $1.5 \%$ agarose gel and visualized by ultraviolet transillumination after staining with ethidium bromide. A negative control was included in each round of PCR to

Table 1 - Primer pairs used in the PCR amplifications.

\begin{tabular}{llll}
\hline Primer & Sequence $\left(5^{\prime}{ }^{\prime}{ }^{\prime}{ }^{\prime}\right)$ & Primer & Sequence (5’'3') \\
\hline mtDNA1H & CTG GTT GAT CCT GCC AGT & mtDNA1L & AGA CTC CTT GGT CCG TGT TTC AAG AC \\
mtDNA2H & AAA CTG GGA TTA GAT ACC CCA CTA T & mtDNA2L & ATG TTT TTG GTA AAC AGG CG \\
mtDNA3H & GGA GAT AAG TCG TAA CAA GGT AAG CA & mtDNA3L & TCC TAC GAT GTT GGG TCC TTT \\
mtDNA4H & AAT CCA GGT CGG TTT CTA TCT A & mtDNA4L & ATC CTA TAT GGG CGA TTG ATG AGT \\
mtDNA5H & CGA AAA TGT TGG TTT ATA CCC TTC C & mtDNA5L & TGC CAA GCT CTG TGG TGA AT \\
mtDNA6H & GGA CTG CAA GAA CAT ATC TCA CAT CAA & mtDNA6L & GGA GGA GGA CAT CCA TGT AGT CAT TC \\
mtDNA7H & GCT CAT TTA TTT CAC TAA CAG CAG T & mtDNA7L & GGG CTA CAG CAA ATT CAA GGA T \\
mtDNA8H & TTG GCT CAC TTT CTA CCT CAA GG & mtDNA8L & GTG GGG ATG ATG ATT TTT AGC ATT GTA \\
mtDNA9H & CCA AAA CAA ATG ATT TCG ACT CA & mtDNA9L & GGT TCC TAA GAC CAA TGG ATT ACT TCT \\
mtDNA10H & TCA CTC TCA CTG CCC AAG AA & mtDNA10L & AGA AGG TTA TAA TTC CTA CG \\
mtDNA11H & GCT GAG ARG GHG TDG GMA TYA TRT C & mtDNA11L & CCT CAG AAK GAT ATY \\
mtDNA12H & CTA ACA TGA ATC GGA GGA CAA CCA G & mtDNA12L & GGC TCA TCT AGG CAT TTT CAG TG \\
\hline
\end{tabular}


check for contamination. The PCR products were stored at $4{ }^{\circ} \mathrm{C}$ until purification and sequencing.

\section{Sequence assembly, annotation and analysis}

The DNASTAR software package (Lasergene version 5.0; Madison, WI) was used for sequence assembly and annotation. The borders of PCGs and rRNA genes were determined by aligning the sequences with those of $C$. albifrons (AJ309866) and H. sapiens (NC_001807) in GenBank. The boundaries and orientations of tRNAs were identified by tRNAscan-SE version 1.21 under default settings. The rates of $\mathrm{Kn}$ and $\mathrm{Ks}$ in PCGs were calculated using PAML version 4 (Yang, 2007). Pairwise distances of selected taxa were inferred from mitochondrial DNA (mtDNA) by MEGA version 5 (Tamura et al., 2011). The complete nucleotide sequence was submitted to GenBank under accession No. JN380205.

\section{Phylogenomic inference using mitogenome}

The complete mitogenomes of C. apella and five other platyrrhine species available from GenBank (Aotus lemurinus, FJ785421; Ateles belzebuth, FJ785422; Callicebus donacophilus, FJ785423; Cebus albifrons, AJ309866; Saimiri sciureus, FJ785425) were used to examine the phylogenomic relationships among these species, with Pan troglodytes (NC_001643) and Homo sapiens (NC_001807) used as outgroups.

Phylogenomic analysis was done with a Maximum likelihood (ML) method implemented in MrBayes 3.1.2 (Huelsenbeck and Ronquist, 2001) and PhyML 3.0 (Guindon et al., 2010). The best fitting model of sequence evolution was obtained by using Modeltest version 3.7 (Posada and Crandall, 1998). The GTR $+\mathrm{I}+\mathrm{G}$ model was selected as the model of best fit. For the Bayesian procedure, four independent MCMC chains were simultaneously run for $5,000,000$ replicates by sampling one tree per 1000 replicates. We discarded the first 1250 trees as part of a burn-in procedure and used the remaining 3750 sampling trees (of which log likelihoods converged to stable values) to construct a $50 \%$ majority rule consensus tree. Two independent runs were used to provide additional confirmation of the convergence of the posterior probability distribution. In the ML analysis, a BIONJ tree was used as a starting tree to search for the ML tree with the GTR $+\mathrm{I}+\mathrm{G}$ model. The robustness of the phylogenetic results was tested by bootstrap analysis with 1000 replicates.

\section{Results and Discussion}

\section{Genome organization and composition}

The complete mitogenome of C. apella is a circular molecule with $16,538 \mathrm{bp}$ (Figure 1). This size is intermediate to that of other primate mitogenomes (Matsui et al., 2009; Matsudaira and Ishida, 2010; Roos et al., 2011), with the longest being 17,149 bp (Eulemur macaco) (Matsui et

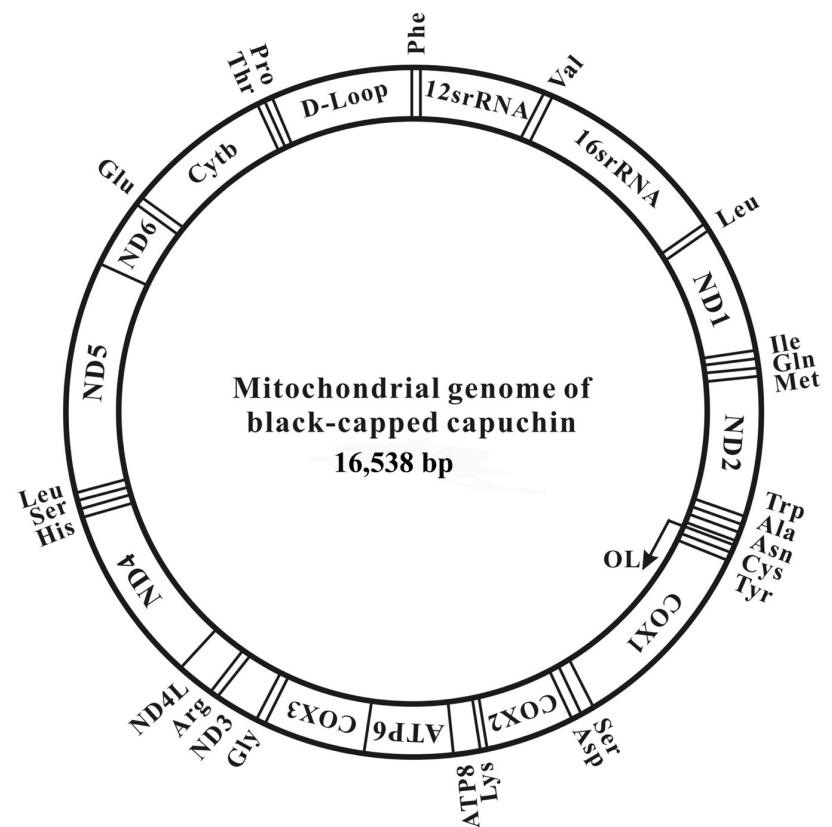

Figure 1 - Gene organization of C. apella mitochondrial DNA. NDI-6 refers to NADH dehydrogenase subunits 1-6, COI-III refers to cytochrome c oxidase subunits 1-3, ATP6 and ATP8 refer to ATPase subunits 6 and 8 , and Cyt $b$ refers to cytochrome $\mathrm{b}$.

al., 2009) and the shortest being 15,467 bp (Pygathrix nemaeus) (Roos et al., 2011). The number and arrangement of genes were the same as those of other primate mitogenomes (Boore, 1999). Table 2 shows the various features of the genome, together with the inferred start and stop codons. The complete mitogenome consisted of two rRNAs, 22 tRNAs, 13 PCGs and a control region. As expected, two rRNAs, 14 tRNAs and 12 PCGs were encoded on the H-strand, while the ND6 gene and eight tRNAs were encoded on the L-strand. Most of the PCGs were separated by one or more tRNAs.

The nucleotide composition of the $C$. apella mitogenome was biased towards adenine (A) and thymine (T), and the overall $\mathrm{A}+\mathrm{T}$ content was $60.6 \%$. There were seven regions in which genes overlapped by $70 \mathrm{bp}$ and 15 intergenic spacer regions that were $57 \mathrm{bp}$ in size.

\section{Protein coding genes and codon usage}

There were no significant differences in the sizes of the C. apella PCGs compared to other primates (Arnason et al., 1996). Most of the 13 PCGs began with an ATG start codon, except for ND2 and ND3 (ATT), COII and ND4L (GTG) and ND6 (TTA). Six PCGs (ND1 (TA), COII, COIII, ND2, ND3 and ND4 (T)) did not terminate with a complete stop codon triplet (Table 2). In mammalian mitogenomes, some peptide-coding genes end with $\mathrm{T}$ or TA rather than with a complete stop codon; in such cases, the terminal nt is contiguous with the $5^{\prime}$ terminal nt of a tRNA gene (Wolstenholmde, 1992; Arnason et al., 1996) and post-transcriptional polyadenylation can modify the in- 
Table 2 - Organization of the C. apella mitochondrial genome.

\begin{tabular}{|c|c|c|c|c|c|c|c|}
\hline \multirow[t]{2}{*}{ Gene } & \multicolumn{2}{|c|}{ Position $^{\mathrm{a}}$} & \multirow[t]{2}{*}{ Size (bp) } & \multirow{2}{*}{$\begin{array}{l}\text { Spacer }(+) / \\
\text { overlap (-) }\end{array}$} & \multirow[t]{2}{*}{ Strand $^{\mathrm{b}}$} & \multicolumn{2}{|c|}{ Codon } \\
\hline & From & To & & & & $\operatorname{Start}^{\mathrm{c}}$ & Stop $^{c}$ \\
\hline tRNA-Phe & 1 & 70 & 70 & & $\mathrm{H}$ & & \\
\hline $12 \mathrm{~s}-\mathrm{rRNA}$ & 71 & 1030 & 960 & & $\mathrm{H}$ & & \\
\hline tRNA-Val & 1031 & 1088 & 58 & & $\mathrm{H}$ & & \\
\hline 16s-rRNA & 1089 & 2651 & 1563 & & $\mathrm{H}$ & & \\
\hline tRNA-Leu (UUR) & 2652 & 2726 & 75 & 2 & $\mathrm{H}$ & & \\
\hline$N D 1$ & 2729 & 3684 & 956 & & $\mathrm{H}$ & ATG & $\mathrm{TA}^{\mathrm{d}}$ \\
\hline tRNA-Ile & 3685 & 3753 & 69 & -3 & $\mathrm{H}$ & & \\
\hline tRNA-Gln & 3751 & 3822 & 72 & 3 & $\mathrm{~L}$ & & \\
\hline tRNA-Met & 3826 & 3890 & 65 & 2 & $\mathrm{H}$ & & \\
\hline$N D 2$ & 3893 & 4931 & 1039 & & $\mathrm{H}$ & ATT & $\mathrm{T}^{\mathrm{d}}$ \\
\hline tRNA-Trp & 4932 & 4998 & 67 & 8 & $\mathrm{H}$ & & \\
\hline tRNA-Ala & 5007 & 5074 & 68 & 1 & $\mathrm{~L}$ & & \\
\hline tRNA-Asn & 5076 & 5148 & 73 & 2 & $\mathrm{~L}$ & & \\
\hline $\mathrm{OL}$ & 5151 & 5184 & 34 & -2 & $\mathrm{~L}$ & & \\
\hline tRNA-Cys & 5183 & 5249 & 67 & -1 & $\mathrm{~L}$ & & \\
\hline tRNA-Tyr & 5249 & 5317 & 69 & 1 & $\mathrm{~L}$ & & \\
\hline COI & 5319 & 6875 & 1557 & -13 & $\mathrm{H}$ & ATG & AGG \\
\hline tRNA-Ser(UCN) & 6863 & 6931 & 69 & 3 & $\mathrm{~L}$ & & \\
\hline tRNA-Asp & 6935 & 7002 & 68 & & $\mathrm{H}$ & & \\
\hline COII & 7003 & 7690 & 688 & & $\mathrm{H}$ & GTG & $\mathrm{T}^{\mathrm{d}}$ \\
\hline tRNA-Lys & 7691 & 7755 & 65 & & $\mathrm{H}$ & & \\
\hline ATP8 & 7756 & 7956 & 201 & -40 & $\mathrm{H}$ & ATG & TAA \\
\hline ATP6 & 7917 & 8597 & 681 & 24 & $\mathrm{H}$ & ATG & TAA \\
\hline COIII & 8622 & 9405 & 784 & & $\mathrm{H}$ & ATG & $\mathrm{T}^{\mathrm{d}}$ \\
\hline tRNA-Gly & 9406 & 9472 & 67 & & $\mathrm{H}$ & & \\
\hline ND3 & 9473 & 9818 & 346 & 1 & $\mathrm{H}$ & ATT & $\mathrm{T}^{\mathrm{d}}$ \\
\hline tRNA-Arg & 9820 & 9888 & 69 & 1 & $\mathrm{H}$ & & \\
\hline$N D 4 L$ & 9890 & 10186 & 297 & -7 & $\mathrm{H}$ & GTG & TAA \\
\hline ND4 & 10180 & 11554 & 1375 & & $\mathrm{H}$ & ATG & $\mathrm{T}^{\mathrm{d}}$ \\
\hline tRNA-His & 11555 & 11623 & 69 & & $\mathrm{H}$ & & \\
\hline tRNA-Ser(AGY) & 11624 & 11682 & 59 & & $\mathrm{H}$ & & \\
\hline tRNA-Leu(CUN) & 11683 & 11753 & 71 & 2 & $\mathrm{H}$ & & \\
\hline ND5 & 11756 & 13561 & 1806 & -4 & $\mathrm{H}$ & ATG & TAA \\
\hline ND6 & 13558 & 14091 & 534 & & $\mathrm{~L}$ & TTA & TAA \\
\hline tRNA-Glu & 14092 & 14160 & 69 & 4 & $\mathrm{~L}$ & & \\
\hline Cyt $b$ & 14165 & 15301 & 1137 & 2 & $\mathrm{H}$ & ATG & TAA \\
\hline tRNA-Thr & 15304 & 15373 & 70 & 1 & $\mathrm{H}$ & & \\
\hline tRNA-Pro & 15375 & 15442 & 68 & & $\mathrm{~L}$ & & \\
\hline Control region & 15443 & 16538 & 1096 & & $\mathrm{H}$ & & \\
\hline
\end{tabular}

${ }^{\mathrm{a}}$ Position numbering starts with the 5 ' position of tRNA-Phe; ${ }^{\mathrm{b}} \mathrm{Genes}$ transcripted from the L or $\mathrm{H}$ strand; ${ }^{\mathrm{c}}$ Start and stop codons of protein coding genes; ${ }^{\mathrm{d}}$ Protein coding genes overlapping with tRNA genes end with an incomplete stop codon.

complete stop codon to a complete one (Ojala et al., 1981; Boore, 2004).

There were 3788 codons in the 13 mitochondrial PCGs, excluding incomplete termination codons. A bias towards a greater proportion of $\mathrm{A}$ and $\mathrm{T}$ is a common feature of primate mitogenomes and results in a corresponding bias in the encoded amino acids (Arnason et al., 1996; Yu et al.,
2011). The overall AT composition of PCGs in C. apella was $60.9 \%$ and the most frequently used amino acids were Leu (12.67\%), Ile (10.32\%), Ser (9.35\%) and Thr (8.98\%).

\section{Ribosomal and transfer RNA genes}

Like other primate mitogenomes, the $C$. apella genome contained small (12S) and large (16S) subunits of 
rRNA (Yu et al., 2011). The 12S rRNA and 16S rRNA were located between the tRNA-Phe and tRNA-Leu (UUR) genes, separated by the tRNA-Val gene. The base compositions of the two rRNA genes were $23.8 \% \mathrm{~T}, 23.6 \% \mathrm{C}$, $35.7 \% \mathrm{~A}$ and $16.9 \% \mathrm{G}$, which generally agreed with the $\mathrm{A}+\mathrm{T}$-rich trend of the whole genome.

Twenty-two tRNA genes were identified based on their respective anticodons and secondary structures, and ranged in size from 58 (tRNA-Val) to 96 (tRNA-Ser) nucleotides. All of the tRNAs folded into a canonical cloverleaf secondary structures, except for tRNA-Phe, tRNAMet, tRNA-Thr, tRNA-Lys and tRNA-Trp. Gene sizes and anticodon nucleotides agreed with those described for other primates. However, G-G, A-C, and especially G-U wobbles and other atypical pairings were identified in the stem regions. These mutations appear to accumulate in mitochondrial genes, partly because mtDNA is not subject to recombinations that would facilitate the elimination of deleterious mutations (Li et al., 2007). The postulated tRNA cloverleaf structures generally contained $7 \mathrm{bp}$ in the aminoacyl stem, $5 \mathrm{bp}$ in the T-stem and the anticodon stem, and $4 \mathrm{bp}$ in the D-stem. Some tRNAs, e.g., tRNA-Val and tRNA-Gly, lacked one or two bp in the T-stem or anticodon stem.

\section{Non-coding regions}

The major non-coding region, i.e., the control region, of $C$. apella was located between the tRNA-Pro and tRNA-Phe genes and contained 1,096 bp. This region can be divided into three domains based on the distribution of variable nucleotide positions and the differential frequencies of nucleotides (Wang et al., 2008). The control region shows marked variability across taxonomic groups and among related species, but its sequence elements related to regulatory functions are highly conserved (Cui et al., 2007). We annotated the regulatory domains of $C$. apella,
H. sapiens and five other platyrrhine species (Figure 2). Termination-associated sequence (TAS) motifs that act as a signal to terminate synthesis of the control region were found at the 5' end of the first domain. There were five conserved sequence boxes (F, E, D, C and B) in the second domain. The third domain had a conserved sequence block (CSB-1) that is important in regulating mtDNA replication. There was less similarity between the sequences of $H$. sapiens and platyrrhine species.

The small non-coding region, a putative origin of light strand replication $\left(\mathrm{O}_{\mathrm{L}}\right)$, was located in a cluster of tRNA-Trp, tRNA-Ala, tRNA-Asn, tRNA-Cys, and tRNATyr (the WANCY region) and consisted of 34 nucleotides. This region could potentially fold into a stable stem-loop secondary structure with $10 \mathrm{bp}$ in the stem and $14 \mathrm{bp}$ in the loop. The conserved motif 5'-GCCCC-3' at the base of the stem within the tRNA-Cys gene has been associated with the transition from RNA synthesis to DNA synthesis.

\section{Mitochondrial DNA variations in five platyrrhine species}

The relative influence of natural selection can be determined by comparing the rates of $\mathrm{Kn}$ versus $\mathrm{Ks}$ in the coding region of protein genes (Jiang et al., 2009). The ND6 gene is generally excluded in such analyses because it is encoded by a different strand of the mtDNA and has a strikingly different nucleotide composition relative to other mitochondrial PCGs (Arnason et al., 1996). As shown in Table 4, the $\mathrm{Kn} / \mathrm{Ks}$ ratios for all pairwise combinations varied among the $12 \mathrm{mtDNA}$ PCGs, suggesting that differential selective constraints have acted on these parameters (Cui et al., 2007). The $\mathrm{Kn} / \mathrm{Ks}$ ratios of the ND1 and ATP8 synthase genes were higher than those of other genes, especially in the ATP8 synthase gene (Table 3). This finding suggests that the ND1 and ATP8 synthase genes may have evolved faster than the other 12 protein-coding genes. Sur-

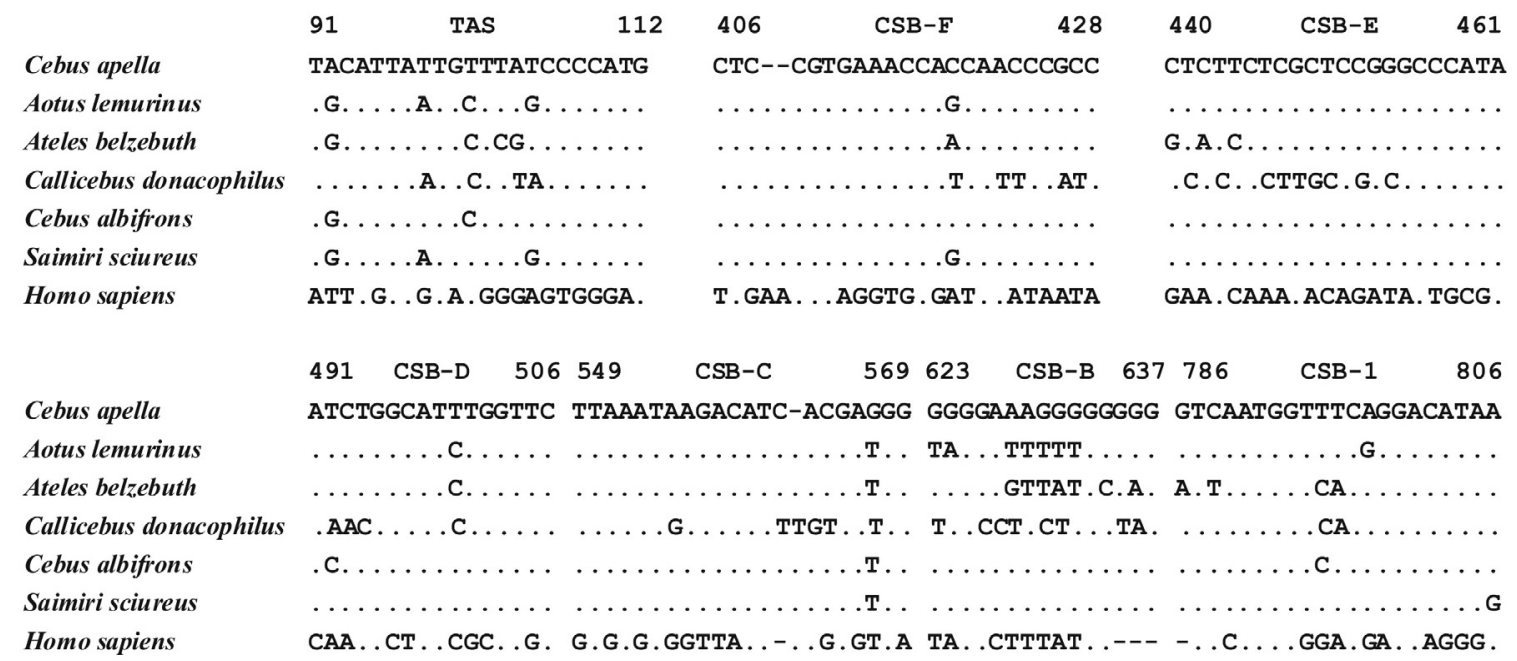

Figure 2 - Sequences and the conserved elements of the control region. Primary sequence features (TAS, CSB-B-F, CSB-1) are shown in boxes. CSB conserved sequence block, TAS - termination-associated sequence. 
prisingly, the COIII gene had a higher mutation rate than the COI and COII genes in C. apella; this is not present in other platyrrhine species (Table 3 ).

\section{Phylogenomic relationships of six platyrrhine species}

Mitochondrial sequences can be used not only to infer phylogenetic relationships and directly trace the evolution of gene rearrangements, but also to provide additional information for phylogenetic reconstructions (Braband et al., 2010). The molecular divergence and separation time of two $C$. apella populations have recently been investigated based on Cyt $b$ sequence data (Casado et al., 2010); this study illustrates the value of mitochondrial sequences in ecological and conservation studies of primates. In contrast to the use of isolated or individual sequences, e.g., the Cyt $b$ sequence, recent molecular studies have tended to use greater larger amounts of DNA data since this allows better tree resolution and provides better agreement with morphological studies (Zhang and Wake, 2009).
A phylogenetic analysis based on the complete mitogenome data from six platyrrhine species (A. lemurinus, $A$. belzebuth, C. donacophilus, C. albifrons, C. apella, and $S$. sciureus) in conjunction with ML and Bayesian methods supported the sister relationship between $C$. apella and $C$. albifrons $(100 \%)$ and the sister relationship between the Aotinae (Aotus) and Cebinae (Cebus/Saimiri) (Figure 3). The results also confirmed the basal position of the Callicebidae and the sister relationship between the Atelinae and Cebidae (Aotinae/Cebinae). These findings were supported by pairwise distance analysis in which the distance between $C$. apella and C. albifrons was the closest while that between $C$. apella and $C$. donacophilus was the greatest, except for the outgroups (Table 4).

Our results generally agreed with the conclusions of recent molecular phylogenetic work on primates (Hodgson et al., 2009; Perelman et al., 2011), although only a few species were included in our tree and the resulting phylogenetic information was too limited. More complete mitogenome data are urgently needed to investigate the

Table 3 - Rates of nonsynonymous (Kn) and synonymous (Ks) substitutions in the coding region of protein genes between C. apella (CA) and other selected species.

\begin{tabular}{|c|c|c|c|c|c|c|c|c|c|c|c|c|c|}
\hline & & $N D 1$ & ND2 & $\mathrm{COI}$ & COII & ATP8 & ATP6 & COIII & ND3 & $N D 4 L$ & ND4 & ND5 & Cytb \\
\hline \multirow{3}{*}{$\begin{array}{l}\text { CA vs. Aotus } \\
\text { lemurinus }\end{array}$} & $\mathrm{Kn}$ & 0.1006 & 0.0374 & 0.0696 & 0.0247 & 0.2739 & 0.0788 & 0.1137 & 0.1030 & 0.2065 & 0.1011 & 0.0876 & 0.0974 \\
\hline & Ks & 0.4646 & 0.5329 & 1.7221 & 0.7899 & 0.9370 & 1.7521 & 0.5318 & 0.7523 & 1.1656 & 0.7157 & 0.7056 & 0.7364 \\
\hline & $\mathrm{Kn} / \mathrm{Ks}$ & .2165 & 0.0702 & 0.0404 & 0.0313 & 0.2923 & 0.0450 & 0.2138 & 0.1369 & 0.1772 & 0.1413 & 0.1241 & 0.1323 \\
\hline \multirow{3}{*}{$\begin{array}{l}\text { CA vs. Ateles } \\
\text { belzebuth }\end{array}$} & $\mathrm{Kn}$ & 0.0834 & 0.0638 & 0.0650 & 0.0219 & 0.1307 & 0.0791 & 0.1183 & 0.0913 & 0.2330 & 0.1244 & 0.0883 & 0.1033 \\
\hline & Ks & 0.4783 & 0.2887 & 1.1512 & 0.8163 & 0.8265 & 0.7954 & 0.5712 & 0.9008 & 1.1331 & 0.6564 & 0.7272 & 0.8174 \\
\hline & $\mathrm{Kn} / \mathrm{Ks}$ & 0.1744 & 0.2210 & 0.0565 & 0.0268 & 0.1581 & 0.0994 & 0.2071 & 0.1014 & 0.2056 & 0.1895 & 0.1214 & 0.1264 \\
\hline \multirow{3}{*}{$\begin{array}{l}\text { CA vs. } \\
\text { Callicebus } \\
\text { donacophilus }\end{array}$} & $\mathrm{Kn}$ & 123 & 0.1129 & 0.0655 & 0. & 0.2278 & 0.0668 & 0.1096 & 0 & 62 & 51 & 0.1173 & 0.0994 \\
\hline & $\mathrm{Ks}$ & 0.5766 & 0.4131 & 1.5320 & 1.0386 & 1.6108 & 1.5649 & 0.5616 & 0.9902 & 1.2670 & 0.7773 & 0.9081 & 0.7466 \\
\hline & $\mathrm{Kn} / \mathrm{Ks}$ & 0.2138 & 0.2733 & 0.0428 & 0.0230 & 0.1414 & 0.0427 & 0.1952 & 0.1297 & 0.1864 & 0.1622 & 0.1292 & 0.1331 \\
\hline \multirow{3}{*}{$\begin{array}{l}\text { CA vs. Cebus } \\
\text { albifron }\end{array}$} & $\mathrm{Kr}$ & 0 & 3 & 0.0645 & 0 & 0 & 6 & 6 & 0 & 642 & 0.0114 & 9 & 33 \\
\hline & Ks & 0.2169 & 0.2871 & 0.7228 & 0.2723 & 0.3057 & 0.2850 & 0.1887 & 0.9300 & 1.0462 & 0.0158 & 0.2918 & 0.1476 \\
\hline & $\mathrm{Kn} / \mathrm{Ks}$ & 0.2503 & 0.0428 & 0.0892 & 0.0419 & 0.2764 & 0.1144 & 0.3158 & 0.0786 & 0.2525 & 0.7215 & 0.1230 & 0.2256 \\
\hline \multirow{3}{*}{$\begin{array}{l}\text { CA vs. Saimiri } \\
\text { sciureus }\end{array}$} & $\mathrm{Kn}$ & 0.100 & 0.0050 & $0.07 / 1$ & 0.0514 & 0.4101 & 0.1044 & 0.1039 & 0.1 & 30 & 0.1346 & 0.0980 & 0.1016 \\
\hline & Ks & 0.5351 & 0.6005 & 1.2448 & 0.6911 & 0.6818 & 1.0097 & 0.5786 & 0.9967 & 2.3726 & 0.6817 & 0.7731 & 0.7969 \\
\hline & $\mathrm{Kn} / \mathrm{Ks}$ & 0.1998 & 0.1059 & 0.0603 & 0.0454 & 0.6059 & 0.1034 & 0.1796 & 0.1413 & 0.1108 & 0.1974 & 0.1268 & 0.1275 \\
\hline
\end{tabular}

Table 4 - Pairwise distances of selected platyrrhine species inferred from the mitochondrial genome.

\begin{tabular}{|c|c|c|c|c|c|c|c|c|}
\hline & 1 & 2 & 3 & 4 & 5 & 6 & 7 & 8 \\
\hline \multicolumn{9}{|l|}{ 1. Cebus albifrons } \\
\hline 2. Cebus apella & 0.100 & & & & & & & \\
\hline 3. Saimiri sciureus & 0.213 & 0.225 & & & & & & \\
\hline 4. Ateles belzebuth & 0.199 & 0.210 & 0.217 & & & & & \\
\hline 5. Callicebus donacophilus & 0.223 & 0.237 & 0.239 & 0.210 & & & & \\
\hline 6. Aotus lemurinus & 0.189 & 0.203 & 0.201 & 0.175 & 0.211 & & & \\
\hline 7. Homo sapiens & 0.320 & 0.326 & 0.323 & 0.309 & 0.325 & 0.314 & & \\
\hline 8. Pan troglodytes & 0.320 & 0.325 & 0.322 & 0.305 & 0.324 & 0.311 & 0.096 & \\
\hline
\end{tabular}




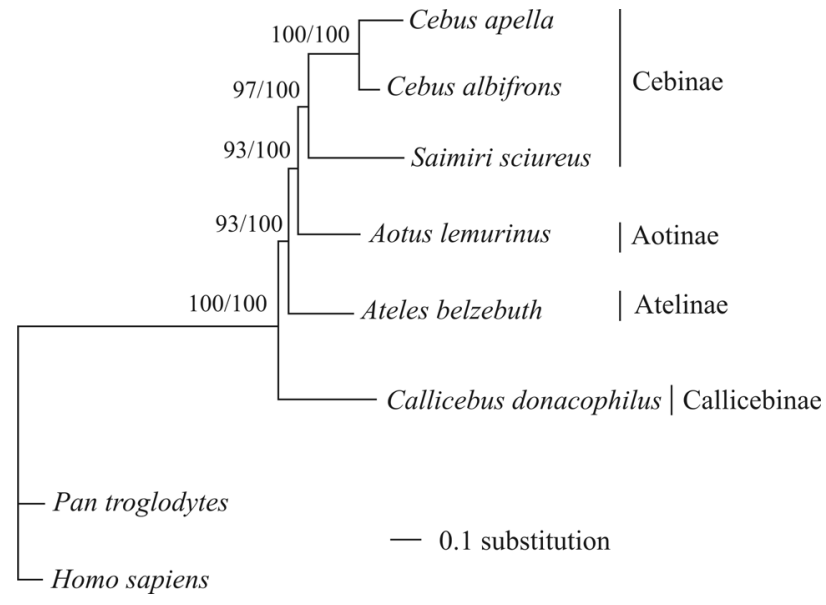

Figure 3 - Maximum likelihood (ML) and Bayesian tree based on complete mitochondrial genome with the GTR $+\mathrm{I}+\mathrm{G}$ model. The horizontal length of each branch corresponds to the substitution rates estimated with the model. Pan troglodytes and Homo sapiens were used as outgroups. Numbers on the branches are bootstrap values for ML and Bayesian posterior probability.

phylogeny of the Cebidae, Platyrrhini and primates in general. The sequence data presented here provide a contribution to this long-term goal.

\section{Acknowledgments}

We thank Kunming Zoo for providing the tissue samples of C. apella. This work was supported by the Natural Scientific Foundation of China (grants 30800605 and 31171189) and the Natural Scientific Foundation of Shandong Province, China (grant ZR2009DZ003).

\section{References}

Amaral PJS, Finotelo LFM, De Oliveira EHC, Pissinatti A, Nagamachi CY and Pieczarka JC (2008) Phylogenetic studies of the genus Cebus (Cebidae-Primates) using chromosome painting and G-banding. BMC Evol Biol 8:169.

Arnason U, Gullberg A and Xu XF (1996) A complete mitochondrial DNA molecule of the white-handed gibbon, Hylobates lar, and comparison among individual mitochondrial genes of all hominoid genera. Hereditas 124:185-189.

Arnason U, Gullberg A, Burguete AS and Janke A (2000) Molecular estimates of primate divergences and new hypotheses for primate dispersal and the origin of modern humans. Hereditas 133:217-228.

Boore JL (1999) Survey and summary of animal mitochondrial genomes. Nucleic Acids Res 27:1767-1780.

Boore JL (2004) Complete mitochondrial genome sequence of Urechis caupo, a representative of the phylum Echiura. BMC Genomics 5:67.

Braband A, Cameron SL, Podsiadlowski L, Daniels SR and Mayer G (2010) The mitochondrial genome of the onychophoran Opisthopatus cinctipes (Peripatopsidae) reflects the ancestral mitochondrial gene arrangement of Panarthropoda and Ecdysozoa. Mol Phylogenet Evol 57:285-292.
Campbell V and Lapointe FJ (2011) Retrieving a mitogenomic mammal tree using composite taxa. Mol Phylogenet Evol 58:149-156.

Casado F, Bonvicino CR, Nagle C, Comas B, Manzur TD, Lahoz MM and Seuanez HN (2010) Mitochondrial divergence between 2 populations of the hooded capuchin, Cebus (Sapajus) cay (Platyrrhini, Primates). Heredity 101:261-269.

Cui P, Ji R, Ding F, Qi D, Gao HW, Meng H, Yu J, Hu SN and Zhang HP (2007) A complete mitochondrial genome sequence of the wild two-humped camel (Camelus bactrianus ferus): An evolutionary history of Camelidae. BMC Genomics 8:241-245.

Fragaszy D, Visalberghi E and Fedigan LM (2004) The Complete Capuchin Monkey: The Biology of the Genus Cebus. Cambridge University Press, Cambridge, 356 pp.

Garcia-Cruz R, Pacheco S, Brieño MA, Steinberg ER, Mudry MD, Ruiz-Herrera A and Garcia-Caldés M (2011) A comparative study of the recombination pattern in three species of Platyrrhini monkeys (primates). Chromosoma 120:521530.

Goodman M, Porter CA, Czelusniak J, Page SL, Schneider H, Shoshani J, Gunnell G and Groves CP (1998) Toward a phylogenetic classification of primates based on DNA evidence complemented by fossil evidence. Mol Phylogenet Evol 9:585-598.

Groves CP (2001) Primate Taxonomy. Smithsonian Institution Press, Washington, DC, 350 pp.

Guindon S, Dufayard JF, Lefort V, Anisimova M, Hordijk W and Gascuel O (2010) New algorithms and methods to estimate maximum-likelihood phylogenies: Assessing the performance of PhyML 3.0. Syst Biol 59:307-321.

Hayasaka K, Gojobori T and Horai S (1988) Molecular phylogeny and evolution of primate mitochondrial DNA. Mol Biol Evol 5:626-644.

Hodgson JA, Sterner KN, Matthews LJ, Burrell AS, Jani RA, Raaum RL, Stewart CB and Disotell TR (2009) Successive radiations, not stasis, in the South American primate fauna. Proc Natl Acad Sci USA 106:5534-5539.

Horovitz I, Zardoya R and Meyer A (1998) Platyrrhine systematics: A simultaneous analysis of molecular and morphological data. Am J Phys Anthropol 106:261-281.

Huelsenbeck JP and Ronquist F (2001) MRBAYES: Bayesian inference of phylogenetic trees. Bioinformatics 17:754-755.

Ingman M, Kaessmann H, Paabo S and Gyllensten U (2000) Mitochondrial genome variation and the origin of modern humans. Nature 408:708-713.

Jiang F, Miao YW, Liang W, Ye HY, Liu HL and Liu B (2009) The complete mitochondrial genomes of the whistling duck (Dendrocygna javanica) and black swan (Cygnus atratus): Dating evolutionary divergence in Galloanserae. Mol Biol Rep 37:3001-3015.

Kay RF (1990) The phyletic relationships of extant and fossil Pitheciinae (Platyrrhini, Anthropoidea). J Hum Evol 19:175-208

Krajewski C, Sipiorski JT and Anderson FE (2010) Complete mitochondrial genome sequences and the phylogeny of cranes (Gruiformes, Gruidae). Auk 127:440-452.

Li XY, Ogoh K, Ohba N, Liang XC and Ohmiya Y (2007) Mitochondrial genomes of two luminous beetles, Rhagophthalmus lufengensis and R. ohbai (Arthropoda, Insecta, Coleoptera). Gene 392:196-205. 
Matsudaira K and Ishida T (2010) Phylogenetic relationships and divergence dates of the whole mitochondrial genome sequences among three gibbon genera. Mol Phylogenet Evol 55:454-459.

Matsui A, Rakotondraparany F, Munechika I, Hasegawa M and Horai S (2009) Molecular phylogeny and evolution of prosimians based on complete sequences of mitochondrial DNAs. Gene 441:53-66.

Meyer D, Rinaldi ID, Ramlee H, Farajallah DP, Hodges JK and Roos C (2011) Mitochondrial phylogeny of leaf monkeys (genus Presbytis, Eschscholtz, 1821) with implications for taxonomy and conservation. Mol Biol Evol 59:311-319.

Mittermeier RA and Coimbra-Filho AF (1981) Systematics: Species and subspecies. In: Coimbra-Filho AF and Mittermeier RA (eds) Ecology and Behavior of Neotropical Primates. Volume 1. Academia Brasileira de Ciências, Rio de Janeiro, pp 29-109.

Moreira MAM (2002) SRY evolution in Cebidae (Platyrrhini, Primates). J Mol Evol 55:92-103.

Nieves M, De Oliveira EHC, Amaral PJS, Nagamachi CY, Pieczarka JC, Mühlmann MC and Mudry MD (2011) Analysis of the heterochromatin of Cebus (Primates, Platyrrhini) by micro-FISH and banding pattern comparisons. J Genet 90:111-117.

Nijman V, Nekaris KAI, Donati G, Bruford M and Fa J (2011) Primate conservation: Measuring and mitigating trade in primates. Endang Species Res 13:159-161.

Nowak RM, Konstant WR and Rylands AB (1999) Walker's Primates of the World. Johns Hopkins University Press, Baltimore, pp 113-115.

Ojala D, Montoya J and Attardi G (1981) tRNA punctuation model of RNA processing in human mitochondria. Nature 290:470-474

Opazo JC, Wildman DE, Prychitko T, Johnson RM and Goodman M (2006) Phylogenetic relationships and divergence times among New World monkeys (Platyrrhini, Primates). Mol Phylogenet Evol 40:274-280.

Perelman P, Johnson WE, Roos C, Seuanez HN, Horvath JE, Moreira MA, Kessing B, Pontius J, Roelke M, Rumpler Y, et al. (2011) A molecular phylogeny of living primates. PLoS Genetics 7:e1001342.

Posada D and Crandall KA (1998) Modeltest: Testing the model of DNA substitution. Bioinformatics 14:817-818.

Raaum RL, Sterner KN, Noviello CM, Stewart CB and Disotell TR (2005) Catarrhine primate divergence dates estimated from complete mitochondrial genomes: Concordance with fossil and nuclear DNA evidence. J Hum Evol 48:237-257.

Ray DA, Xing J, Hedges DJ, Hall MA, Laborde ME, Anders BA, White BR, Stoilova N, Fowlkes JD, Landry KE, et al. (2005) Alu insertion loci and platyrrhine primate phylogeny. Mol Phylogenet Evol 35:117-126.

Roos C, Zinner D, Kubatko LS, Schwarz C, Yang M, Meyer D, Nash SD, Xing J, Batzer MA, Brameier M, et al. (2011) Nuclear versus mitochondrial DNA: Evidence for hybridization in colobine monkeys. BMC Evol Biol 11:77-89.

Schneider H, Schneider MPC, Sampaio I, Harada ML, Stanhope M, Czelusniak J and Goodman M (1993) Molecular phylog- eny of the New World monkeys (Platyrrhini, Primates). Mol Phylogenet Evol 2:225-242.

Schrago CG (2007) On the time scale of New World primate diversification. Am J Phys Anthropol 132:344-354.

Silva Júnior JS (2002) Taxonomy of capuchin monkeys Cebus Erxleben, 1777. Neotrop Primates 10:1-29.

Sorenson MD, Ast JC, Dimcheff DE, Yuri T and Mindell DP (1999) Primers for a PCR-based approach to mitochondrial genome sequencing in birds and other vertebrates. Mol Phylogenet Evol 12:105-114.

Steiper ME and Ruvolo M (2003) New World monkey phylogeny based on X-linked G6PD DNA sequences. Mol Phylogenet Evol 27:121-130.

Stewart CB and Disotell TR (1998) Primate evolution - In and out of Africa. Curr Biol 8:R582-588.

Tamura K, Peterson D, Peterson N, Stecher G, Nei M and Kumar S (2011) MEGA 5: Molecular evolutionary genetics analysis using maximum likelihood, evolutionary distance, and maximum parsimony methods. Mol Biol Evol 28:27312739.

Wang CH, Chen Q, Lu GQ, Xu JW, Yang QL and Li SF (2008) Complete mitochondrial genome of the grass carp (Ctenopharyngodon idella, Teleostei): Insight into its phylogenic position within Cyprinidae. Gene 424:96-101.

Wildman DE, Jameson NM, Opazo JC and Yi SV (2009) A fully resolved genus level phylogeny of neotropical primates (Platyrrhini). Mol Phylogenet Evol 53:694-702.

Wilson DE and Reeder DM (2005) Mammal Species of the World: A Taxonomic and Geographic Reference. Johns Hopkins University Press, Baltimore, 2142 pp.

Wolstenholmde R (1992) Animal mitochondrial DNA: Structure and evolution. Int Rev Cytol 141:173-216.

Yang ZH (2007) PAML 4: A program package for phylogenetic analysis by maximum likelihood. Mol Biol Evol 24:15861591.

Yu L, Wang XP, Ting N and Zhang YP (2011) Mitogenomic analysis of Chinese snub-nosed monkeys: Evidence of positive selection in NADH dehydrogenase genes in high altitude adaptation. Mitochondrion 11:497-503.

Zhang L, Nie LW, Zhang Y, Rui JL and Zhang YY (2008) Complete sequence and organization of the mitochondrial genome of Cyclemys atripons (Testudines, Geoemydidae). Genet Mol Biol 31:783-788.

Zhang P and Wake DB (2009) Higher-level salamander relationships and divergence dates inferred from complete mitochondrial genomes. Mol Phylogenet Evol 53:492-508.

\section{Internet Resources}

tRNAscan-SE version 1.21, http://www.genetics.wustl.edu/eddy/tRNAscan-SE/ gust 12, 2011)

\section{Associate Editor: Fabrício Rodrigues dos Santos}

License information: This is an open-access article distributed under the terms of the Creative Commons Attribution License, which permits unrestricted use, distribution, and reproduction in any medium, provided the original work is properly cited. 